\title{
1 Optimization of extraction and purification process of hyaluronic acid from
}

\section{2 fish eyeball.}

3

4 M.A. Murado ${ }^{1}$, M.I. Montemayor ${ }^{1}$, M.L. Cabo ${ }^{2}$, J.A. Vázquez ${ }^{1 *}$, M.P. González ${ }^{1}$

5

$6 \quad{ }^{1}$ Grupo de Reciclado y Valorización de Materiales Residuales (REVAL)

$7 \quad$ Instituto de Investigacións Mariñas (CSIC)

8 r/ Eduardo Cabello n ${ }^{\circ}$ 6. Vigo-36208 Galicia (Spain)

9 Tel: $+34986214468 /+34986231930$

10 Fax: +34986292762

11

$12 \quad{ }^{2}$ Grupo de Microbiología y Tecnología de Productos Marinos

13 Instituto de Investigacións Mariñas (CSIC)

$14 \mathrm{r} /{\text { Eduardo Cabello }{ }^{\circ}}^{0}$ 6. Vigo-36208 Galicia (Spain)

15

16 *Corresponding author, e-mail: jvazquez@iim.csic.es

17

18 Headline: Purification of hyaluronic acid from fish eyeball.

19 
The goal of the present work is to optimize the different steps for obtaining highly purified hyaluronic acid (HA) from fish eyeball. The extraction and purification process of HA from vitreous humour of fish, among other biological materials, is based on the succession of: 1) a step of protein electrodeposition, previous or simultaneous with a diafiltration process in total recirculation, 2) a selective recovery in hydroalcoholic solution of impure sediments obtained by alcoholic exhaustive precipitation, 3) an alkaline treatment under hydroalcoholic solution and controlled conditions of alkalinity, temperature, proportion of ethanol and time that it precipitates HA and solubilizes proteins, and 4) HA recovery by alkaline suspension of the precipitate in hydroalcoholic phosphate monosodium that it dissolves HA, neutralizes the extract and leaves insoluble proteins in the sediment. Thus, HA with high purity (more than 99.5\%), useful for clinical and cosmetic applications, are obtained by means of low-cost process using a waste material.

Keywords: Hyaluronic acid; fish by-products; bioprocessing; environment; food processing; downstream processing.

\section{INTRODUCTION}

HA is a polymer formed by repeating disaccharide units of $\mathrm{N}$-acetyl-D-glucosamine and glucuronic acid. This glycosaminoglycan is present in tissues as cartilage, sinovial fluid, skin, rooster combs, umbilical cord and vitreous humour and sinovial fluid, besides in the cell wall of bacteria such a Streptococcus zooepidemicus (Shiedlin et al., 2004; Yamada and Kawasaki, 2005; Vázquez et al., 2009). In recent years, an increasing interest has been reported due to its numerous applications as cosmetic and pharmaceutical compound (Nerem, 2006; Kim et al., 2008; DeAngelis, 2008; Zhang et al., 2008). The habitual sources for its industrial production are rooster crest, bovine synovial liquid, bovine vitreous humour and, with rising offer, bacterial 
cultivations (Shiedlin et al., 2004; Huang et al., 2008; Vázquez et al., 2010). However, vitreous humour from eyeball of certain fishes also contains appreciable concentrations of HA that it could establish rational uses of these waste materials by upgrading. It would help to reduce environmental pollution on coastal areas. This substrate would also avoid the risk of bovine spongiform encephalopathy (BSE) that bovine origin generates. Furthermore, commercial prices of HA obtained from animal sources like vitreous humour is much higher than that obtained by fermentation. In Table 1, HA concentrations from various sources are summarized.

The main problem of HA purification is the elimination of the proteins that are being part of proteoglycan matrix and they are potentially allergenic in many applications of the product. The final concentration of proteins in the preparations should be around of $\sim 5-10 \mu \mathrm{g}$ of protein per mg of HA for clinical uses that imply injection, descending the demands of purity in non injectable performances (perfusion, topical application, oral administration). With a source as vitreous humour of swordfish, it means to take the relationship protein/HA from an initial value of $\sim 45$ until a final value of $\sim 0.01$.

The fundamentals of many of the purification procedures reported in recent literature are already described in Rodén et al. (1972). These stages can be summarized in the following terms:

a) In aqueous solution, proteins and HA precipitate together when ethanol is added in the appropriate proportion. A part of the proteins, variable according to the source, are not solubilised to the ethanol concentrations to those HA still remains in solution. It makes that fractional precipitation can be employed as a potential resource of partial purification.

b) A part of the proteins, variable according to the source, can be also hydrolyzed by means of protease action (papain, alkalase, trypsin, pronase). Thus, the subsequent treatment of the 
hydrolysates with ethanol leaves on hydroalcoholic solution a part of the hydrolysis products, whereas the remains of the proteases are still distributed between the soluble fraction and the sediment.

An example of the application of these properties, economically viable with rich sources, it is in the patent of Cullis-Hill (1989) that improves other previous works and that it is based on the recurrent execution of alcoholic precipitations and enzymatic hydrolysis, repeated as many times as necessary to achieve the suitable purity. On the other hand, in this work ethanol is used with $2 \%(\mathrm{w} / \mathrm{v})$ of acetic acid what develops the irreversible denaturalization of the proteins in the precipitation steps.

Other interesting works that use technical of chromatographic separation (Kitagawa et al., 1990) or reactions with salts of quaternary ammonium (Hildesheim, 1987) do not constitute, however, precedent of the process that we are proposing. In same circumstances they are the procedures that, still using ultrafiltration techniques (Yoshizawa, 1990), are applied in terms and with concrete objectives different from those are presented in this article. According to our knowledge, no works of extraction and purification of HA from vitreous humour of fishes have been reported until now.

In the present study, a process for HA recovery and purification from vitreous humour of selected species of fishes is described. Thus, a combination of steps of ultrafiltration-diafiltration system, protein electrodeposition, selective resolubilization in hydroalcoholic medium and selective precipitation in alkaline hydroalcoholic solution is studied and optimized. 


\section{MATERIALS AND METHODS}

\section{Vitreous humour preparation}

Eyeballs from swordfish (Xiphias gladius) and shark (Prionace sp.) were obtained from the fish port of Vigo and frozen at $-20^{\circ} \mathrm{C}$. Subsequently, these frozen eyeballs were undergone to two or three serial cuts. The fragments were defrosted on a warp of parallel threads of nylon (meshes with knots elevate the losses and time of process besides generating a bigger proportion of impurities) that allows the leak of vitreous humour and it retains optic capsule including lens. Subsequently, this material was homogenized, in order to complete the deconstruction of the humour, and clarified by centrifugation at $6,000 \times g$ for $15 \mathrm{~min}$. Three clear phases were obtained: sediment of impurities, a little fraction of lipid supernatant (easily removed by aspiration) and a majority interface of viscous vitreous humour.

\section{Ultrafiltration-diafiltration system}

Ultrafiltration-diafiltration was performed by means of plate polysulfone membranes (Millipore Minitan System) of $60 \mathrm{~cm}^{2}$ with cut-off at 100, 300 and $675 \mathrm{kD}$, using an assembly with total recirculation at $35^{\circ} \mathrm{C}$. A pack of 4 plate membranes (surface total area $=240 \mathrm{~cm}^{2}$ ) were employed.

\section{Electrodeposition system}

The electrodeposition device was performed by means of two platinum electrodes of $50 \mathrm{~cm}-$ length and prepared in spiral/cylindric format. The electric current established between both electrodes was variable in the range of $10-40 \mathrm{~mA}$.

\section{Alcoholic precipitation and selective recovery of the precipitate}


121 The retentates obtained from electrodeposition and diafiltration steps were salted with $\mathrm{NaCl}$

$1220.5 \mathrm{M}$ and slowly precipitated with ethanol $99-100 \%$ under intensive agitation to avoid the 123 formation of floccules.

125 This hydroalcoholic solution is incubated to $\sim 5^{\circ} \mathrm{C}$ and sediment is spontaneously precipitated in

126 3-5 hours of incubation. The corresponding clear supernatant is drained by means of a peristaltic 127 pump and it is rejected. The sediment, including HA and a protein fraction, is redissolved, by 128 intensive agitation, adding the volume of water that is necessary to obtain a appropriate 129 water:ethanol relationship to quantify HA and to maximize the unsolubilized protein fraction 130 (see section 3 of results and discussion). The suspension, in the appropriate relationship of 131 water:ethanol, is diluted with a hydroalcoholic solution (with the same relationship) until a 132 volume approximately equivalent to $1 / 5$ of the initial retentate. Subsequently, it is clarified by 133 centrifugation $(6,000 \times g$ for $15 \mathrm{~min})$ being now the sediment rejected (it only contains insoluble 134 protein) and the supernatant recovered.

\section{Alkaline process on hydroalcoholic solution}

137 Experimental plan implied a rotatable design of two variables (see below): $S$, or $\mathrm{NaOH}$ 138 concentration in the reaction mixture, with domain $[0.45 ; 0.85 \mathrm{M}]$, and $E$, or volumes of ethanol 139 per volume of retentate, with domain [0.6;0.9]. The corresponding tests were carried out adding

140 to the previous hydroalcoholic extract, slowly and with vigorous agitation at $5^{\circ} \mathrm{C}$ for $1-5 \mathrm{~h}$, 141 hydroalcoholic solutions of $\mathrm{NaOH}$ in the required proportions to obtain reaction mixtures with 142 the pre-established values of $S$ and $E$.

144 When the agitation is interrupted, a mass of cottony aspect precipitates and it can be separated by 145 centrifugation at $6,000 \times g$ for $15 \mathrm{~min}$. The discarded supernatant contains the protein fraction 146 solubilised by the treatment. The alkaline sediment that contains HA together with an insoluble 
147 protein fraction is firstly redissolved in a small volume of water:ethanol (1:0.75) solution, adding

148 as well an aqueous solution of $\mathrm{NaH}_{2} \mathrm{PO}_{4} 0.5 \mathrm{M}$ :ethanol (1:0.75) in order to neutralize or to take

149 the $\mathrm{pH}$ in a established value. It should be pointed out that the use of acids as $\mathrm{HCl}$ or acetic for

150 this purpose presents the risk of reducing the average molecular mass of HA causing losses in

151 the retentate at $300 \mathrm{kD}$ (Tømmeraas and Melander, 2008). The homogeneous resolution obtained

152 is centrifuged $(6,000 \times g$ for $15 \mathrm{~min})$ and the corresponding supernatant with HA is collected.

153 The protein sediment is washed with water:ethanol (1:0.75) and the supernatant is joined with

154 the previous one.

155

\section{Analytical methods}

157 HA assay was a slight modification of the method of Van Den Hoogen et al. (1998) following

158 the proposal and mathematical corrections defined by Murado et al. (2005). Proteins were

159 determined by the method of Lowry et al. (1951). HA molecular weight was determined by size-

160 exclusion chromatography on HPLC by means of an Ultrahydrogel Linear column (Waters,

161 USA) with $0.1 \mathrm{M} \mathrm{NaNO}_{3}$ as mobile phase (flow= $0.6 \mathrm{~mL} / \mathrm{min}$ ) and a refractive-index detector.

162 The column was calibrated with polystyrene standards (Sigma) of varying molecular weights

$163(32,77,150,330,990$ and $2600 \mathrm{kD})$.

164

165 Experimental design and statistical methods

166 In all cases that the joint effect of two variables was studied, an approach using rotatable designs,

167 with central quintuple replication, was carried out (Akhnazarova and Kafarov, 1982; Box et al.,

168 2005). Experimental domain and coding criteria are given in Table 2. The results of the factorial

169 designs were fitted to equations of the type:

170

$171 Z=b_{0}+b_{1} X+b_{2} Y+b_{12} X Y+b_{11} X^{2}+b_{22} Y^{2}$ 
173 Statistical significance of the coefficients was verified by means of Student's $t$-test $(\alpha<0.05)$, and

174 model consistency by means Fisher's $F$-test $(\alpha<0.05)$ applied to following mean squares ratios:

$F_{1}=$ Model $/$ Total error the model is acceptable if

$F_{2}=($ Model + Lack of fitting $) /$ Model

$F_{1} \geq F_{\text {den }}^{\text {num }}$

$F_{3}=$ Total error / Experimental error

$F_{2} \leq F_{\text {den }}^{\text {num }}$

$F_{4}=$ Lack of fitting / Experimental error

$F_{3} \leq F_{d e n}^{\text {num }}$

$F_{4} \leq F_{d e n}^{\text {num }}$

177 Although it is a common practice to limit this test to the $F_{1}$ or $F_{1}$ and $F_{2}$ quotients, it should be

178 pointed out that $F_{3}$ and $F_{4}$ are essential to avoid the introduction of irrelevant variables or

179 variable combinations in this type of empiric models.

180

RESULTS AND DISCUSSION

182

\section{1: Initial diafiltration-concentration process}

183 Initially, clarified vitreous humour is diafiltrated using a system with total recirculation and a

184 value of dilution flow between the half and the third part of permeation flow. When two membranes of cut-off at 675 and $100 \mathrm{kD}$ are sequentially applied to a volume $\mathrm{V}_{0}$, we can obtain:

a) A retentate from $675 \mathrm{kD}$ with a lower volume than $\mathrm{V}_{0} / 10$, that it contains, at least, $75 \%$ of $\mathrm{HA}$ total and approximately $16 \%$ of the initial protein.

b) A permeate with an approximate volume of $2 \mathrm{~V}_{0}$ that is diafiltrated at $100 \mathrm{kD}$ until a retentate

191 volume between $\mathrm{V}_{0} / 10$ and $\mathrm{V}_{0} / 15$. This retentate contains the $25 \%$ remaining and a $29 \%$ of

192 initial protein. The corresponding permeate, with the remaining protein fraction and without HA,

193 is rejected. Although the ratio protein/HA increases in these second retentates with regard to the

194 corresponding value in the raw material, the elimination of this protein in the subsequent steps is

195 slightly more efficient with retentates than using raw materials. 
197 When a cut-off at $300 \mathrm{kD}$ is only used, it is possible to achieve a retentate with an approximate 198 volume of $\mathrm{V}_{0} / 12$ that it contains $96 \%$ of $\mathrm{HA}$ and $46 \%$ of the initial protein.

\section{2: Protein electrodeposition}

201 It was carried out inserting electrodeposition device into the clarified vitreous humour and 202 establishing between both electrodes an initial electric current of $10 \mathrm{~mA}$. This value was 203 gradually increased until $40 \mathrm{~mA}$ for $1 \mathrm{~min}$ and was maintained in this level for $30 \mathrm{~min}$. As consequence of this current step, in few seconds a deposit not very soluble in water and soluble in $\mathrm{NaOH} 0.5 \mathrm{M}$ was formed in the anode. This precipitate produces a strongly positive reaction of Lowry-proteins. The fact that the electrode washing with distilled water generates a suspension

207 with an approximate $\mathrm{pH} 4.2$ suggests that the process implies the interchange of electrons towards anode from carboxyl groups of the proteins with net negative charge (cathode reaction: $\left.\mathrm{H}^{+}+\mathrm{e}^{-}=\mathrm{H}\right)$. These proteins precipitate when they approach to the isoelectric point. On the other hand, the deposit detached from the electrode remains unsolubilized for at least one hour and it

212 been repeatedly reported (Wong et al., 1981; Hawkins and Davies, 1996; Balogh et al., 2003), 213 the use of platinum electrodes did not affect to the proportions of HA retained at 300 and 675 $\mathrm{kD}$.

The interest of the protein fraction so removed (approximately $0.3 \mathrm{~g}$ of protein per liter of 217 vitreous humour, with a current of $40 \mathrm{~mA}$ for $15 \mathrm{~min}$ ) comes from its effects on the diafiltration 218 efficiency. Deposits obtained with same electric current values in raw vitreous humour and with retentates from diafiltration at $675 \mathrm{kD}$ reduced to a volume of $\mathrm{V}_{0} / 5$, indicating that these are non filterable materials to this cut-off and contribute to increase transmembrane pressure with the 221 progress of the process. In fact, when electrodeposition begins after a time period of enough 
diafiltration so that the permeate flow falls to $50 \%$ of the initial value, recoveries of this flow until $90 \%$ of initial value are observed.

Therefore, electrodeposition can be carried out as a previous or simultaneous operation to the diafiltration. Although in Faraday's laws the solute concentration implied in the electrode reactions are not present in the mathematical equations, the protein amount deposited by unit of time increases with the retentate concentration (data not shown). This effect is easily understandable since the progress of the diafiltration eliminates chemical species of low molecular mass, able to compete with non filterable proteins in the anode reaction. A previous deposition process, followed or not by a centrifugation step, can be combined with diafiltration, case in which a prefilter (e.g., nylon mesh of 40-100 $\mu \mathrm{m})$ should be used. In all cases, deposition efficiency increases with a brief wash the anode in $\mathrm{NaOH}$ solution when accumulated protein layer reduces the electric current to inadequate values.

\section{3: Alcoholic precipitation and selective recovery of the precipitate}

237 In Figure 1 the joint effect of ethanol and $\mathrm{NaCl}$ on retentates precipitation are depicted. This 238 response was evaluated by means of HA concentration and recovery proteins in extracts obtained 239 by redissolution of the corresponding sediments in water:etanol (1:0.75). The recovery of HA is 240 little affected by salt concentration and increases asymptotically with the proportion of ethanol. 241 However, high concentrations of both variables produces drops, slight but consistent, from a 242 maximum value of HA recovery. On the other hand, recovery of proteins, much more affected 243 by salt concentration, falls when salt concentration increasing at any considered level of ethanol.

244 Meanwhile, the response to the ethanol loses the asymptotic nature, falling from a maximum 245 when salt concentration decreases. 
247 Figure 1 shows the appropriate range for the precipitation process. These experimental profiles 248 revealed that proportions of ethanol no lower than 1.5 volumes per volume of retentate and salt 249 concentrations higher than 1.5 $\mathrm{M}$ in the retentate should be used for optimal HA recovery. Lower 250 values of ethanol can lead to losses of HA and lower values of salt do not affect to HA recovery 251 but they led to extracts with higher protein concentrations.

253 Regarding the sediment redissolution, a convenient water:ethanol relationship is 1:0.75 in an 254 approximately equivalent volume to $1 / 5$ of retentate. Higher proportions of ethanol present the 255 risk of HA losses, mainly in retentates with high concentration ratios. However, lower 256 proportions do not affect to the HA recovery but they contribute unnecessarily to redissolve 257 proteins (data not shown).

259 Finally, another possible repetition of this step (Figure 2) implies the addition of $\mathrm{NaCl}$ to the 260 retentate until a concentration $0.5 \mathrm{M}$ and 0.5 volumes of ethanol. In this alternative, scarcer 261 protein sediment to the previous proposed procedure is obtained, whereas the whole of HA 262 remains in solution in the supernatant. Though the consumption of ethanol can decrease with 263 regard to the precedent procedure without losses in the recovery of HA, the supernatant that 264 continues to the subsequent stage is more diluted and it contains higher proportions of proteins.

\section{4: Alkaline process}

267 The joint effect of $\mathrm{NaOH}$ and ethanol concentrations on HA recovery after a treatment of $10 \mathrm{~h}$ at $2685^{\circ} \mathrm{C}$ was evaluated by means of a second order experimental design following the approach of 269 Akhnazarova and Kafarov (1982). When independent variables are coded in such way that both natural domains become the codified domain $[-1 ; 1]$ : 
HA recovery (as \%) is satisfactorily fitted to the following empirical equation:

276

$$
H A=93.93-4.46 S-35.25 S E-39.12 S^{2}-5.25 E^{2}
$$

whose coefficients were statistically significant (t-Student test, $\alpha=0.05$ ), and its consistency was proven by means of $F$-Fisher test applied to the relationships $F_{1}, F_{2}, F_{3}$ and $F_{4}(\alpha=0.05)$. Inside the studied interval, the maximum of this equation (2), whose response surface is showed in Figure 3, is placed in the maximum value of ethanol proportion (0.9), with $0.558 \mathrm{M}$ of $\mathrm{NaOH}$.

On the other hand, in Figure 4 (left) the percentage of HA recovery is shown at different times, operating in the maximum of the equation (2). The values that decay until $97 \%$ in 10 hours are satisfactorily fitted to a first order kinetics equation (with $t$ in hours):

$$
H A=100 \cdot \exp (-0.00317 \cdot t)
$$

Figure 4 (right) reveals, moreover, that the effect of the treatment on the proteins distribution between supernatant and sediment hardly varies after first hour, being able to be considered practically immediate.

294 Thus, equations (2) and (3) are able to use for determining the most appropriate conditions in the 295 alkaline treatment, that can be established, at $5^{\circ} \mathrm{C}$, in 0.9 volumes of ethanol, $\mathrm{NaOH} 0.56 \mathrm{M}$ for 296 1-5 hours. 
298 Finally, the extracts from alkaline process can be treated by diafiltration at convenient cut-off 299 membrane to achieve simultaneously the HA concentration and the phosphate dilution required.

300 Furthermore, the soluble proteins remainders, to concentrations in the range of $0.02-0.04 \mathrm{mg} / \mathrm{mL}$, 301 as well as the salts are efficiently removed in this step. If an ulterior purification is still required, 302 it can return to the selective redissolution of the alcoholic precipitate (Figure 3) in similar terms 303 to those described previously.

\section{5: Testing the proposal methodology}

Example 1

A volume of $2.5 \mathrm{~L}$ of swordfish humour vitreous (Xiphias gladius) clarified by centrifugation was undergone, under soft shaking, to electric current of $40 \mathrm{~mA}$ with platinum electrodes. Anode, a mesh of $3 \times 0.5 \mathrm{~cm}$, was washed after 10 min by immersion in $\mathrm{NaOH} 0.5 \mathrm{~N}$ and this operation was repeated twice before diafiltration beginning. Table 2 shows the main parameters of the process step that are described next.

Diafiltration was carried out using membrane of cut-off at $300 \mathrm{kD}$ with total recirculation assembly and nylon mesh of $60 \mu \mathrm{m}$ using as prefilter. Pressure and dilution flow with distilled water were maintained constant at $40-50$ psi and with a $50 \%$ of permeation flow, respectively.

316 Electric current of $40 \mathrm{~mA}$ was also applied for 8 periods of $15 \mathrm{~min}$. The operation was 317 interrupted one time for washing the membrane $\left(15\right.$ min with $\mathrm{NaOH} 0.1 \mathrm{M}$ at $45^{\circ} \mathrm{C}$ without pressure) and prefilter and it was maintained until to reach a retentate volume of $260 \mathrm{~mL}$.

In $250 \mathrm{~mL}$ of retentate, $21.9 \mathrm{~g}$ of $\mathrm{NaCl}(1.5 \mathrm{M})$ were dissolved. Subsequently, $375 \mathrm{~mL}$ of $99 \%$ 321 ethanol were slowly added under magnetic and intense shaking at $5^{\circ} \mathrm{C}$. This agitation system was 322 maintained for $30 \mathrm{~min}$ and it was afterwards left in rest to the same temperature overnight. In 323 these conditions, compact sediment and a clarified and rejected supernatant of $425 \mathrm{~mL}$ were 
324 obtained. The sediment was mixed with $60 \mathrm{~mL}$ of water:ethanol (1:0.75) under vigorous 325 agitation, until to get a fine and homogeneous suspension that it was centrifuged $(6,000 \times g$ for

$32615 \mathrm{~min}$ ), recovering now the supernatant. This last sediment was washed with $20 \mathrm{~mL}$ of 327 water:ethanol (1:0.75) joining the corresponding supernatant with the previous one.

$32975 \mathrm{~mL}$ from the whole of the supernatants were mixed with $\mathrm{NaOH} 0.56 \mathrm{M}$ in water:ethanol 330 (1:0.9) solution. After $2 \mathrm{~h}$ of intense agitation at $5^{\circ} \mathrm{C}$, the mixture was centrifuged $(6,000 \times g$ for $331 \quad 15 \mathrm{~min})$ at the same temperature being discarded the supernatant. The sediment was redissolved 332 in a total volume of $40 \mathrm{~mL}$ with water:ethanol (1:0.75) and the aqueous solution of $\mathrm{NaH}_{2} \mathrm{PO}_{4}$ 0.5M:ethanol (1:0.75) necessary for obtaining a $\mathrm{pH}$-value of 7.25. The redissolution was 334 centrifuged $(6,000 \times g$ for $15 \mathrm{~min})$, the supernatant was recovered and the sediment was washed 335 with early solutions until similar $\mathrm{pH}$-value, gathering both supernatants.

Finally, an aliquot of $57 \mathrm{~mL}$ from the supernatants were diafiltrated at $100 \mathrm{kD}$ until to obtain 30 $\mathrm{mL}$ of retentate with the characteristics specified in Table 3. In this retentate, the molecular weight of HA was $1600 \mathrm{kD}$.

Example 2

342 A volume of $2.5 \mathrm{~L}$ of shark vitreous humour (Prionace sp.) was perfomed in similar way to example 1 with the differences in the work volumes and HA and proteins concentrations that are

344 specified in Table 3. It should be pointed out that the most advantageous ratio protein:AH is not 345 only translated in a final extract of more volume, concentration and purity, but also in a faster 346 and more efficient process. In this case, the molecular weight of HA in the final solution was $3472000 \mathrm{kD}$. 
A volume of $0.3 \mathrm{~L}$ of veal vitreous humour with an initial concentration of $0.258 \mathrm{mg} / \mathrm{mL}$ of HA

351 was also handled in a similar way to example 1 . In the different fractions, same volumetric 352 relationships with initials were maintained. Thus, a sample I of $12 \mathrm{~mL}$ with $6.35 \mathrm{mg} / \mathrm{mL}$ of HA 353 and $99.4 \%$ of purity was obtained.

\section{CONCLUSIONS}

356 A set of different physical and chemical processes, including protein electrodeposition, 357 separation by membrane (ultrafiltration and diafiltration), as well as selective precipitation and 358 redissolution performance have been optimized in order to extract and to purify HA from 359 humour vitreous of eyeball from fish processing wastes. Solutions of HA with more than $99 \%$ of 360 purify were obtained in the optimal conditions proposed.

\section{ACKNOWLEDGMENTS}

We wish to thank the Xunta de Galicia (project PGIDIT04TAM007001CT) and the UE-Life Araceli Menduiña, Margarita Nogueira and Ana Durán for their excellent technical assistance. The waste materials were kindly supplied by Dilsea S.L. (Port of Vigo, Spain). Part of the results showed in the present work were previously patented ("Nuevo procedimiento de obtención de ácido hialurónico", Spanish Patent No 2192960, 2005)

\section{REFERENCES}

Akhnazarova, S. and Kafarov, V., 1982, Experiment Optimization in Chemistry and Chemical Engineering, MIR Publishers, Moscow.

Balogh, G.T., Illés, J., Székely, Z., Forrai, E. and Gere, A., 2003, Effect of different metal ions on the oxidative damage and antioxidant capacity of hyaluronic acid. Arch Biochem Biophys, 410: 76-82.

Box, G.E.P., Hunter, W.G. and Hunter, J.S., 2005, Statistics for Experimenters: Design, Innovation, and 381 
Cooney, M.J., Goh, L.T., Lee, P.L. and Johns, M.R., 1999, Structured model-based analysis and control of the hyaluronic acid fermentation by Streptococcus zooepidemicus: Physiological implications of glucose and complex-nitrogen-limited growth. Biotechnol Prog, 15: 898-910.

Cullis-Hill, D., 1989, Preparation of hyaluronic acid from synovial fluid. U.S. Pat. No 4,879,375.

DeAngelis, P.L., 2008, Monodisperse hyaluronan polymers: Synthesis and potential applications Cur Pharm Biotechnol, 9: 246-248.

Gherezghiher, T., Koss, M.C., Nordquist, R.E. and Wilkinson, C.P., 1987, Analysis of vitreous and aqueous levels of hyaluronic acid: application of high-performance liquid chromatography. Exp Eye Res, 45: 347-349.

Hawkins, C.L. and Davies, M.J., 1996, Direct detection and identification of radicals generated during the hydroxyl radical-induced degradation of hyaluronic acid and related materials. Free Radical Biol Med, 21: $275-290$.

Hildesheim, J., 1987, Noninflammatory heat-resistant low molecular weight hyaluronic acid, a process for extracting it from crude sources, and compositions containing it. Eur Pat Appl, EP 239335.

Huang, W.C., Chen, S.J. and Chen, T.L., 2008, Production of hyaluronic acid by repeated batch fermentation. Biochem Eng J, 40: 460-464.

Johns, M.R., Goh, L.T. and Oeggerli. A.A., 1994, Effect of pH, agitation and aeration on HA production by Streptococcus zooepidemicus. Biotechnol Lett, 15: 507-512.

Kim, S.K., Ravichandran, Y.D., Khan, S.B. and Kim, Y.T., 2008, Prospective of the cosmeceuticals derived from marine organisms. Biotechnol Bioproc Eng 13: 511-523.

Kitagawa, H., Chiba, S., Saegusa, H. and Miyoshi, T., 1990, Purification of hyaluronic acid. Jap Pat, 02103204.

Lowry, O.H., Rosebrough, N.J., Farr, A.L. and Randall, R.J., 1951, Protein measurement with the folin phenol reagent. J Biol Chem, 193: 265-275.

Murado, M.A., Vázquez, J.A., Montemayor, M.I., Cabo, M.L. and González, M.P., 2005, Two mathematical models for the correction of carbohydrate and protein interference in the determination of uronic acids by the m-hydroxydiphenyl method. Biotechnol Appl Biochem, 41: 209-216.

Nakano, T., Nakano, K. and Sim, J.S., 1994, A simple rapid method to estimate hyaluronic acid concentrations in rooster comb and wattle using cellulose acetate electrophoresis. J Agric Food Chem, 42: 2766-2768.

Nerem, R.M., 2006, Tissue engineering: The hope, the hype, and the future. Tissue Eng, 12:1143-1150.

Rodén, L., Baker, J.R., Cifonelli, J.A. and Mathews, M.B., 1972, Isolation and characterization of connective tissue polysaccharides. Meth Enzymol, XXVIII Part B: 73-140.

Shiedlin, A., Bigelow, R., Christopher, W., Arbabi, S., Yang, L., Maier, R.V., Wainwright, N., Childs, A. and Miller, R.J., 2004, Evaluation of hyaluronan from different sources: Streptococcus zooepidemicus, rooster comb, bovine vitreous and human umbilical cord. Biomacromol, 5: 2122-2127.

Tømmeraas, K. and Melander, C., 2008, Kinetics of hyaluronan hydrolysis in acidic solution at various pH values. Biomacromol, 9: 1535-1540. 
438 Van de Lest, C.H.A., 1998, A microtiter plate assay for the determination of uronic acids. Anal Biochem, 439 257: 107-111.

Vázquez, J.A., Montemayor, M.I., Fraguas, J. and Murado, M.A., 2009, High production of hyaluronic and lactic acids by Streptococcus zooepidemicus in fed-batch culture using commercial and marine peptones from fishing by-products. Biochem Eng J, 44: 125-130.

Vázquez, J.A., Montemayor, M.I., Fraguas, J. and Murado, M.A., 2010, Hyaluronic acid production by Streptococcus zooepidemicus in marine by-products media from mussel processing wastewaters and tuna peptone viscera. Microb Cell Factor, 9: 46. radicals in the degradation of hyaluronic acid induced by metal ions and by ascorbic acid. J Inorg Biochem, 14: 127-134.

Yamada, T. and Kawasaki, T., 2005, Microbial synthesis of hyaluronan and chitin: new approaches. J Biosci Bioeng, 99: 521-528.

Yoshizawa, Y. and Yamada, K., Fukui, F., 1990, Ultrafiltration membrane in purification of high molecular weight hyaluronic acid. Jap Pat, 02047101.

461

462

463

464 


\section{FIGURE CAPTIONS}

Figure 1: HA recovery (up) and protein presented (down) in redissolutions of precipitates obtained with different proportions of $\mathrm{NaCl}$ (molarity in the retentate) and ethanol (volumes per volume of retentate).

Figure 2: Flow diagram of the different operations developed in the preparation of highly purify HA from vitreous humour of fish eyeball. Discontinuous lines (B) show possible repetitions in the stages in order to increase purify of the final samples.

Figure 3: Joint effect of $\mathrm{NaOH}$ concentration and ethanol proportion on HA recovery (\%) in alkaline treatments at $5^{\circ} \mathrm{C}$. Independent variables are codified according the criteria specified in the text. Response surface corresponding to the equation (2).

Figure 4: HA recovery (left) and remain and removed protein (right) by alkaline treatment in the maximum of the equation (3), with different times of incubation. Keys, $\bigcirc$ (left): HA; $\bigcirc$ (right): remain protein in the extract; $\nabla$ : removed protein in the sediment; $\triangle$ : removed protein in the supernatant. Dotted line to the left shows the fits of the HA data to the equation (2). 


\section{TABLE CAPTIONS}

Table 1: Concentrations of HA in various sources.

Table 2: Experimental domain and codification of two independent variables in the factorial rotatable design.

Table 3: Main parameters of the process steps, called according to the Figure 2, that are described in examples 1 (X. gladius) and 2 (Prionace sp.). In volume column, the values into open brackets are the aliquots used in the subsequent step. 


\section{TABLES}

Table 1

\section{SOURCE}

Rooster combs

Bovine synovial liquid

Pig synovial liquid *

Bovine vitreous humour

Pig vitreous humour

Bacterial cultures

Vitreous humour of swordfish(a)

Vitreous humour of shark(b)
$\mathrm{HA}$ (g per liter or $\mathrm{Kg}$ )

8-45

$15-40$

$0.5-6$

0.3

0.04

2-6

0.055

0.3
REFERENCE

Nakano et al., 1994

Cullis-Hill, 1989

PRESENT WORK

Gherezghiher, 1987

PRESENT WORK

Johns et al., 1994 ; Cooney et al., 1999

PRESENT WORK PRESENT WORK

* The farm animals systematically provided concentrations closed to the specified minimum, and very often they practically lacked synovial liquid in their articulations.

(a) Xiphias gladius

(b) Prionace sp.

Table 2

\begin{tabular}{|c|c|c|c|c|c|c|c|c|c|c|}
\hline \multirow{3}{*}{$\begin{array}{c}\text { Variables } \\
\text { X } \\
Y\end{array}$} & & \multicolumn{9}{|c|}{ Experimental matrix in coded values } \\
\hline & & -1 & 1 & -1 & 1 & $-2^{1 / 2}$ & $2^{1 / 2}$ & 0 & 0 & 0 \\
\hline & & -1 & -1 & 1 & 1 & 0 & 0 & $-2^{1 / 2}$ & $2^{1 / 2}$ & 0 \\
\hline If we define & $\begin{array}{l}\text { Vn: } \\
\text { Vc: }\end{array}$ & \multicolumn{9}{|c|}{$\begin{array}{l}\text { natural value, with domain }[\mathrm{m} ; \mathrm{M}] \\
\text { coded value, with domain }\left[-2^{1 / 2} ; 2^{1 / 2}\right]\end{array}$} \\
\hline We can write & $\begin{array}{l}\text { Vo: } \\
\Delta \mathrm{Vn}^{\prime}\end{array}$ & \multicolumn{9}{|c|}{$\begin{array}{l}\text { natural value at the center of the domain }=(m+M) / 2 \\
\text { Increment of natural value corresponding to an unitary increment } \\
\text { of coded value }=(M-m) /\left(2 \times 2^{1 / 2}\right)\end{array}$} \\
\hline \multicolumn{5}{|c|}{ Codification: $V_{c}=\left(V_{n}-V_{0}\right) / \Delta V n$} & \multicolumn{6}{|c|}{ Decodification: $V n=V o+(\Delta V n \times V c)$} \\
\hline
\end{tabular}




\section{Table 3}

\begin{tabular}{|c|c|c|c|c|c|c|c|c|}
\hline \multirow[t]{2}{*}{ Steps } & \multicolumn{2}{|c|}{$\begin{array}{c}\text { Volume } \\
\mathrm{mL}\end{array}$} & \multicolumn{2}{|c|}{$\begin{array}{c}\mathrm{HA} \\
\mathrm{mg} / \mathrm{mL}\end{array}$} & \multicolumn{2}{|c|}{$\begin{array}{l}\text { Protein-Lowry } \\
\mathrm{mg} / \mathrm{mL}\end{array}$} & \multicolumn{2}{|c|}{$\begin{array}{c}\text { HA purity* } \\
\%\end{array}$} \\
\hline & Ex. 1 & Ex. 2 & Ex. 1 & Ex. 2 & Ex. 1 & Ex. 2 & Ex. 1 & Ex. 2 \\
\hline Raw material & 2500 & 2500 & 0.055 & 0.283 & 2.1 & 2.78 & 2.55 & 9.24 \\
\hline Retentate 300 kDa & $260(250)$ & $416(400)$ & 0.508 & 1.617 & 9.6 & 7.68 & 5.03 & 17.39 \\
\hline Supernatant 2 & $80(75)$ & $200(180)$ & 1.540 & 3.072 & 0.52 & 0.42 & 74.76 & 87.97 \\
\hline Supernatant 4 & $60(57)$ & $125(122)$ & 1.848 & 4.202 & 0.038 & 0.022 & 97.99 & 99.48 \\
\hline Simple I & 30 & 100 & 3.370 & 4.818 & 0.009 & 0.007 & 99.73 & 99.85 \\
\hline \multicolumn{9}{|c|}{ HA concentration } \\
\hline
\end{tabular}


FIGURE 1

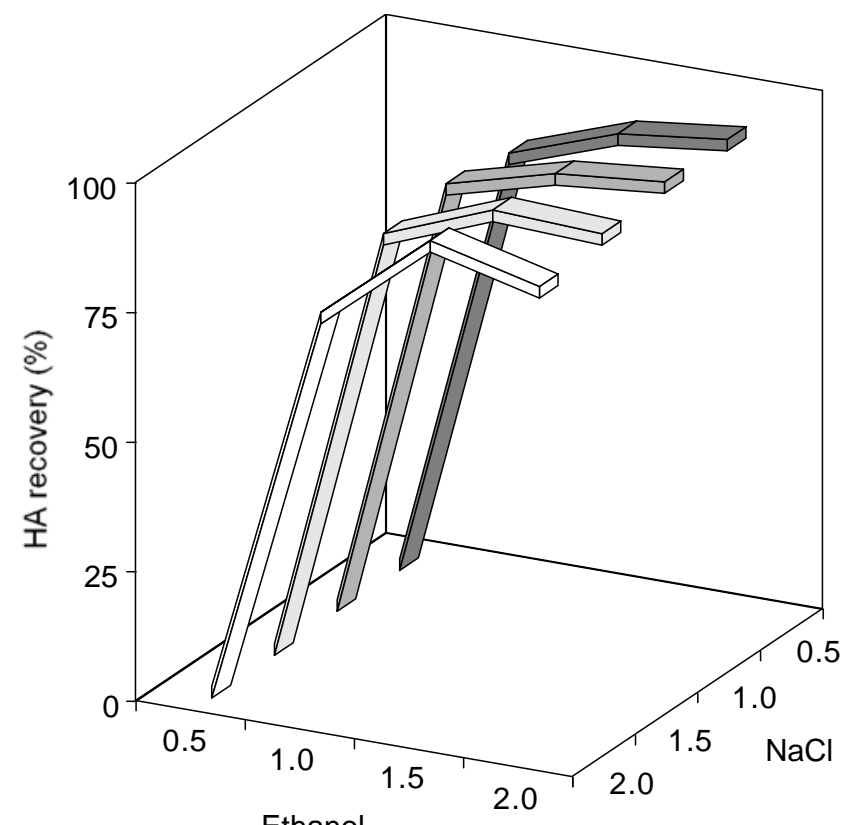

Ethanol

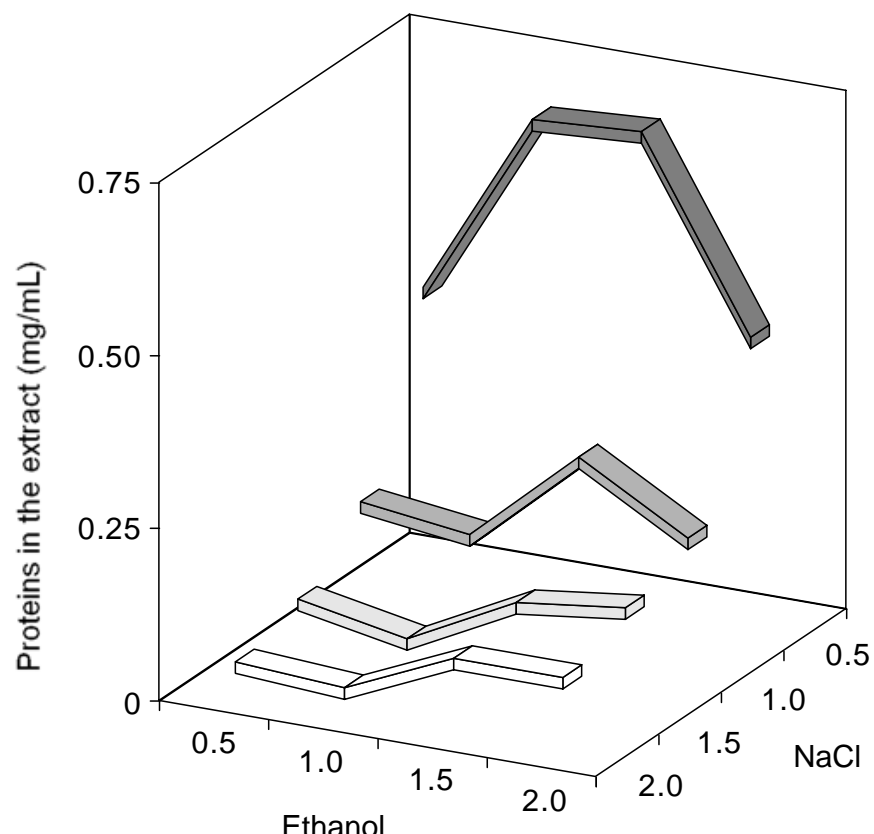




\section{FIGURE 2}

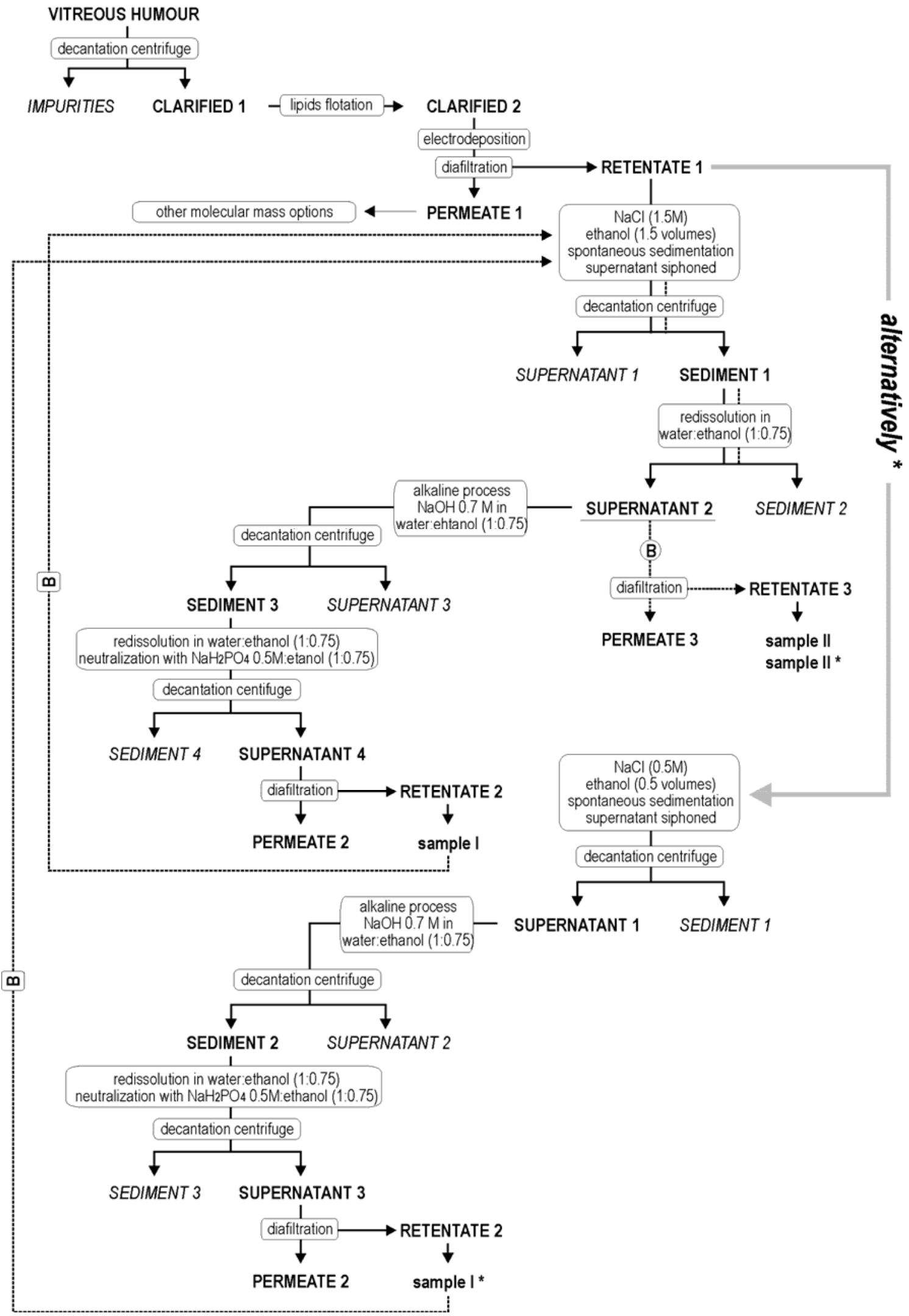


FIGURE 3

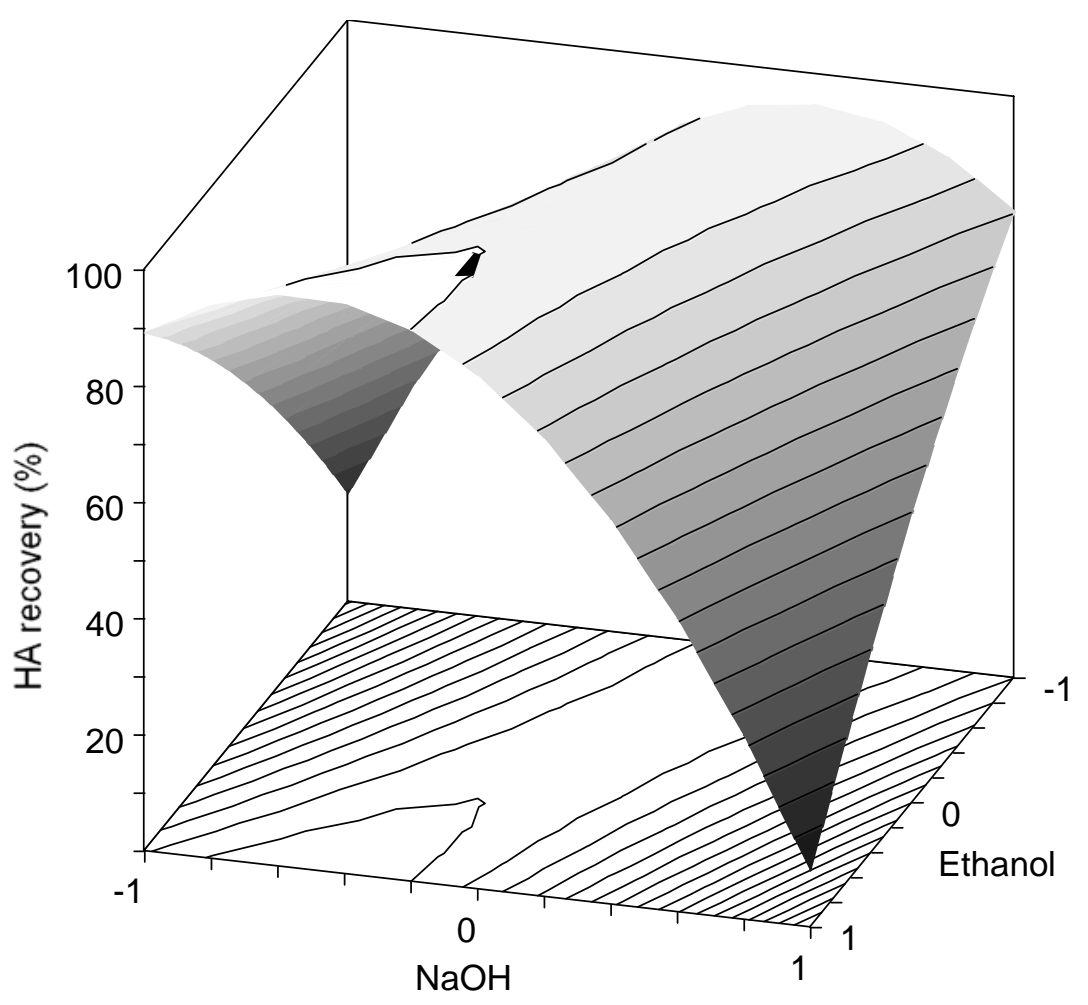


FIGURE 4

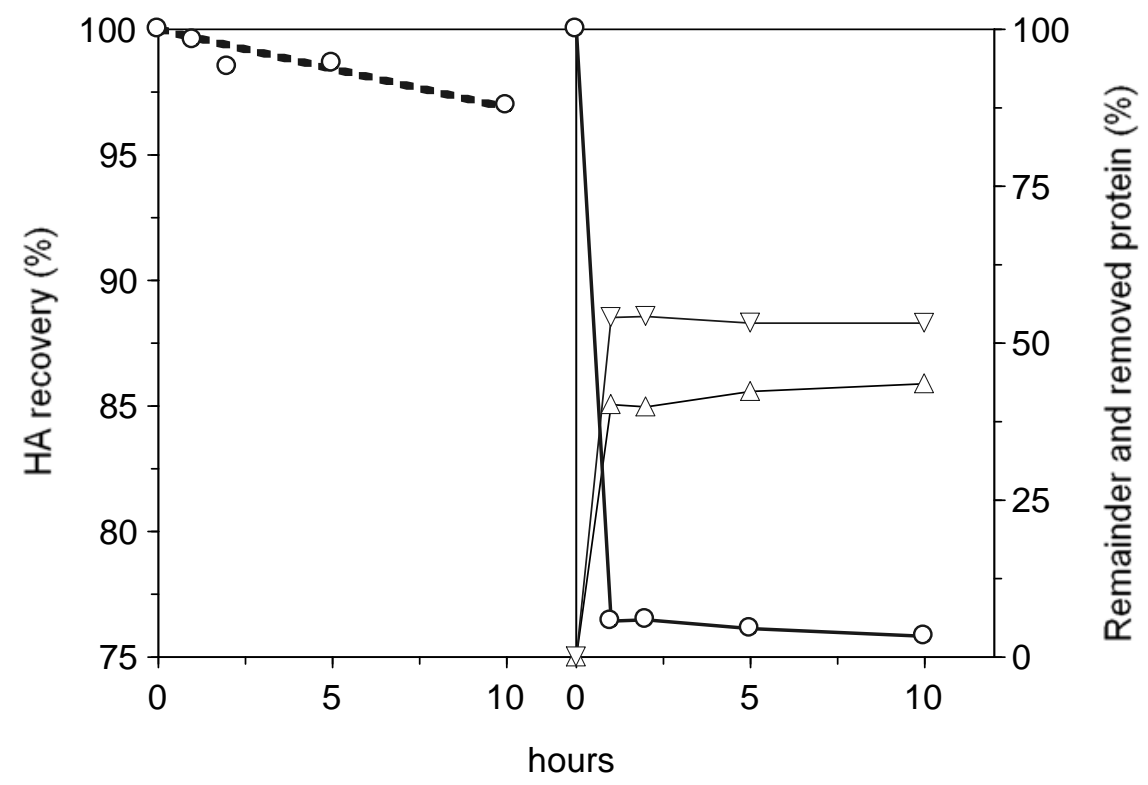

